\title{
Movimento de Mulheres Camponesas (MMC) na defesa da soberania alimentar ${ }^{1}$
}

\author{
Andressa Bertoncello Valandro ${ }^{2}$ \\ Rosana Maria Badalotti ${ }^{3}$ \\ Cristiane Tonezer ${ }^{4}$ \\ Egon Roque Frohlich ${ }^{5}$
}

\begin{abstract}
Resumo
Os movimentos sociais, aqui entendidos como expressões de poder da sociedade civil organizada, têm sido objeto de diferentes discursos, tanto em nível acadêmico quanto dos governos, pressionados a produzir respostas às demandas destes atores sociais coletivos. No Brasil, diversos movimentos sociais emergem nas décadas de 1970 e 1980, juntamente com o processo de redemocratização do país, sendo que, na região do oeste catarinense, destaca-se o surgimento de movimentos relacionados ao campo, como é o caso do Movimento de Mulheres Camponesas (MMC), objeto deste estudo. O MMC caracteriza-se como um movimento popular, feminista e autônomo, que busca a valorização das mulheres do campo, em contraposição à cultura patriarcal, ainda visualizada na sociedade contemporânea. Aposta na construção de um projeto de agricultura camponesa e agroecológica na defesa da soberania alimentar. Através de revisão da literatura e documental, este artigo analisa a organização política do $\mathrm{MMC}$ na defesa de um modelo de desenvolvimento baseado nos princípios da soberania alimentar. Como resultados, evidencia-se que uma das principais bandeiras de luta do MMC refere-se à defesa da vida, considerando a busca por justiça, liberdade e solidariedade, com destaque para a construção de um projeto de agricultura agroecológica em contraposição ao modelo de agricultura convencional. A defesa da soberania alimentar pelo MMC assume questões específicas, como a preservação do solo, a recuperação de sementes crioulas, o plantio e manejo agroecológico, entendendo que não se trata apenas de um conceito, mas de uma estratégia política no enfrentamento ao sistema neoliberal globalizado.
\end{abstract}

Palavras-chave: Movimento social. Mulheres camponesas. Agricultura agroecológica. Soberania alimentar.

\begin{abstract}
Social movements, understood here as expressions of power in a organized civil society, have been object of diferent speeches, both in the academical level and the governments; they're pressured into creating answers to the demands of different collective social agents. In Brazil, several social movements emerged in the 1970's and 1980 's, alongside with the redemocratization process in the country; in the west region of Santa Catarina, the emergence movements related to the countryside stand out, for exemple, the Peasant Women's Movement $(M M C)$, this study's object. The MMC is a popular, feminist and autonomous movement that strives for the appreciation of peasant women, in contrast to the patriarcal culture, which is still seen in contemporary society. The movement bets on the building of a peasant agriculture agroecology project in the defense of Food Sovereignty. Trough revision of literature and data, this article analyzes the political organization of MMC in the defense of a development model based on the principles of Food Sovereignty. As a result, it's visible that one of the main fight flags of MMC refers to the defense of life, considering the pursuit of justice, freedom and

\footnotetext{
${ }^{1}$ Uma versão preliminar deste artigo foi publicada nos Anais do 10 Seminário Nacional de Desenvolvimento Regional: sustentabilidade socioeconômica e ambiental no contexto regional, realizado em abril de 2016, nas Faculdades Integradas de Taquara - FACCAT/RS.

${ }^{2}$ Universidade Comunitária da Região de Chapecó/SC - UNOCHAPECÓ. andressa_bertoncello@hotmail.com

${ }^{3}$ Universidade Comunitária da Região de Chapecó/SC - UNOCHAPECÓ. rosana@unochapeco.edu.br

${ }^{4}$ Universidade Comunitária da Região de Chapecó/SCRS - UNOCHAPECÓ. tonezer@unochapeco.edu.br

${ }^{5}$ Professor do Programa de Pós-Graduação em Desenvolvimento Rural (PGDR) da UFRGS e do Programa de Pós-Graduação em Desenvolvimento Regional da FACCAT/RS. egonfrohlich@terra.com.br
} 
solidatiry, with a highlight to the building of a agroecologic agriculture project in contrast to the conventional agriculture model. The defense of Food Soverignty by MMC admits specific matters, like soil preservation, recovery of criolle seeds, agroecologic planting and management, having in mind that it isn't only about a concept, but a political strategy when facing the globalized neoliberal system.

Keywords: Social movements. Peasant women. Agroecological agriculture. Food soverignty.

\section{Introdução}

Os movimentos sociais, como expressões de poder da sociedade civil organizada, segundo Gohn (2006), têm sido objeto de diferentes análises e preocupações, tanto em nível acadêmico, a partir de produções teóricas em distintas áreas do saber, quanto nas esferas governamentais. Estas, cada vez mais têm sido pressionadas a produzir respostas às demandas e reivindicações desses atores sociais coletivos.

No Brasil, entre as décadas de 1970 e 1980, a efervescência e consolidação de vários movimentos sociais coincidem com o processo de redemocratização do país. Nesse processo, a sociedade civil foi às ruas contra um regime ditatorial, contribuindo com a constituição de um estado democrático de direito e com a formulação de políticas públicas que atendessem às demandas da população. Da mesma forma, Poli (2008) afirma que, nesse período, emergiram na região oeste de Santa Catarina importantes movimentos sociais do campo. A essa região estão relacionados, quer ao seu modo de vida, quer à reprodução social, o Movimento dos Trabalhadores Rurais Sem Terra (MST), o Movimento de Oposição Sindical, o Movimento dos Atingidos por Barragens (MAB) e o Movimento de Mulheres Camponesas (MMC), este último objeto deste estudo. Na atualidade, esses movimentos continuam com forte representatividade nacional.

O MMC caracteriza-se como um movimento popular, feminista e autônomo, que busca a valorização das mulheres do campo em contraposição à cultura patriarcal (CINELLI, 2013). A participação das mulheres como protagonistas de espaços decisórios contribui para a construção de um projeto de agricultura camponesa e agroecológica que se opõe aos padrões impostos pela produção em grande escala e favorece à soberania alimentar.

De acordo com a Associação de Mulheres Trabalhadoras Rurais da Região Sul do Brasil (AMTR/SUL, 2008, p. 29), na agricultura camponesa o trabalho familiar visa garantir uma produção diversificada e voltada para o autossustento, combinando a produção vegetal 
com a criação de animais durante o ano inteiro. Para o $M M C$, as práticas com sementes crioulas estão relacionadas à soberania alimentar, que implica a produção de alimentos saudáveis, com proteção aos setores domésticos e às culturas locais. Observa-se, neste caso, a importância do trabalho feminino na pequena propriedade, em especial no cultivo para o autoconsumo da família.

Nesse sentido, o recorte para o estudo ora apresentado visa analisar, por meio de revisão de literatura e documental, a organização política do MMC na defesa de um modelo de desenvolvimento baseado nos princípios da soberania alimentar e da agricultura camponesa e agroecológica. Para o alcance do objetivo traçado neste artigo, o texto foi dividido em dois itens, que visam explorar algumas questões importantes para elucidar o que se pretende. O primeiro item contempla uma descrição dos movimentos sociais, o histórico desses movimentos no Brasil e no oeste catarinense, e a questão da soberania alimentar como um projeto defendido pelos camponeses e camponesas. No segundo item, aborda-se especificamente o Movimento de Mulheres Camponesas (MMC) e a soberania alimentar como um princípio orientador das suas ações. Por fim, são tecidas algumas considerações a partir do estudo desenvolvido.

\section{Conceituando movimentos sociais}

Goss e Prudêncio (2004, p. 75) afirmam que qualquer discussão sobre o tema movimentos sociais traz consigo uma questão importante: "[...] afinal, o que são movimentos sociais?". Tentando responder à questão, os autores apresentam significados distintos, que variam de acordo com a concepção segundo a qual se desenvolve cada estudo. Nesse sentido, o conceito de movimentos sociais, no campo da ciência, não é unívoco e unilateral, suscitando diferentes explicações e interpretações teóricas. A intenção neste espaço não é esgotar um assunto tão amplo, mas apontar algumas considerações que auxiliam no alcance do objetivo proposto para este artigo em específico.

Gohn (2006) aponta que a dificuldade na sistematização de um conceito sobre esses movimentos se deve tanto às transformações ocorridas em relação aos objetivos e demandas dos atores sociais coletivos, quanto às mudanças socioeconômicas da sociedade. 
Com isso, esses atores fazem com que as suas ações apresentem mudanças ao longo do tempo.

$\mathrm{Na}$ tentativa de propor algumas demarcações, para pensar os movimentos sociais, Gohn (2006; 2011) analisa, a partir do campo da política, os movimentos sociais como expressões de poder da sociedade civil, que sempre ocorrem em contextos de força social. A autora afirma que essas demarcações não podem ser limitadoras das discussões sobre o tema, mas que representem um referencial a partir do qual se discuta e se reflita sobre as práticas desses atores sociais. Ainda, segundo essa autora, os movimentos sociais podem ser entendidos como ações sociopolíticas promovidas por diferentes atores coletivos. São espaços não institucionalizados de formulação de identidades coletivas, sustentadas por princípios valorativos, políticos e ideológicos, que são compartilhados pelos atores pertencentes a um grupo. Isso não significa, de acordo com a autora, que esses espaços sejam isentos de contradições e conflitos internos.

Araujo e Lima (2010) afirmam que, a partir da década de 1980, as transformações sociais e a intensificação da globalização fizeram com que os movimentos sociais assumissem contornos diferentes das formas tradicionais, incumbindo novos desafios à produção teórica da área. Assim, estudiosos iniciam um processo de estabelecimento de diálogos e integração entre distintos enfoques teóricos.

Nesta busca pela integração, Araujo e Lima (2010) exploram as aproximações entre dois teóricos - Melucci e Tarrow ${ }^{2}$. O primeiro apoia-se no paradigma da identidade coletiva, e o segundo, no paradigma do processo político. Na visão das autoras, ambos têm influências na produção teórica sobre os movimentos sociais no Brasil.

Ao postular a noção de identidade coletiva, Melucci (2001) entende que sua construção é definida e negociada nas relações sociais entre os atores, implicando densas interações nas dimensões afetivas e emocionais. "A identidade coletiva é aquilo que une os indivíduos em um nó" (ARAUJO; LIMA, 2010, p. 120). Assim, entende-se a identidade não como essência, mas como produto de trocas, negociações, solidariedade, decisões e conflitos entre os atores, os quais ocorrem no cotidiano das relações, ou seja, em nível

\footnotetext{
${ }^{2}$ Araujo e Lima (2010), em revisão teórica sobre os movimentos sociais, apontam que o campo empírico que envolve o tema é extenso e diversificado, resultando em muitos modelos e abordagens diferentes para interpretá-los. Visam, por meio do estudo, verificar aproximações e divergências entre os teóricos Melucci e Tarrow.
}

COLÓQUIO - Revista do Desenvolvimento Regional - Faccat - Taquara/RS - v. 15, n. 1, jan./jun. 2018 
micro. A construção da identidade coletiva para Melucci (2001) é a base do processo de construção de um sistema de ação dos movimentos sociais.

A preocupação de Tarrow (2009), por sua vez, toma para si a análise na proporção de nível macro, pois está centrada nas interações estratégicas entre os movimentos sociais e seu meio de ação, enfatizando os contextos político e social. Utiliza o termo confronto para se referir à ação coletiva dos sujeitos que, privados do acesso regular às instituições, desafiam os outros e/ou as autoridades, buscando dar visibilidade às suas exigências e reivindicações (novas ou ainda não atendidas).

Os pressupostos de Melucci (2001) e Tarrow (2009) partem do mesmo problema: encontrar um suporte teórico para a análise dos movimentos sociais. O que difere são os princípios que embasam o olhar de cada um. São marcados pela divergência de abordagem teórico-metodológica na análise do fenômeno: “[...] micro versus macro, política versus cultura, objetividade versus subjetividade, etc". Entretanto, para além do antagonismo presente nos princípios de Melucci e Tarrow, Araujo e Lima (2010) afirmam que aquilo que está no plano de frente de um autor está no plano de fundo do outro, e isso permite a aproximação entre ambos:

\footnotetext{
Nas sociedades contemporâneas, em que o global e local estão imbricados, não se pode estabelecer que os conflitos sejam apenas culturais e simbólicos. $\mathrm{Na}$ diversidade de interesses que hoje perpassa as relações humanas, o poder sai da esfera estatal para a esfera cotidiana das relações pessoais, e este fato não deve ser desconsiderado das análises acadêmicas. Acreditamos que os conflitos são resultados sim de disputa de poder simbólico, mas não somente este, pois os poderes político e econômico também fazem parte de nossas relações (ARAUJO; LIMA, 2010, p. 127).
}

Nesta perspectiva de integração entre micro e macro, política e cultura, objetividade e subjetividade, no sentido de superar esses dualismos, buscamos trazer subsídios para a análise da construção da identidade coletiva. Esta ocorre nas relações internas do movimento analisado - MMC, assim como seu protagonismo na defesa de um princípio compartilhado com outros movimentos sociais, que ocorre diretamente no campo da política. 
2.1 Trajetória dos movimentos sociais no Brasil: organização política e resistência

No Brasil, as décadas de 1960, 1970 e início dos anos 1980 são marcadas como um período de autoritarismo da ditadura militar. Entretanto, apesar de toda a repressão e violência, diversos movimentos sociais eclodem, reivindicando a garantia da dignidade humana, expressas na busca pela cidadania (GOHN, 2011; SCHERER-WARREN, 2012).

O processo de redemocratização ocorrido no Brasil no fim dos anos 1970 e início dos anos 1980 foi promissor para os movimentos. Nesse período ocorreu uma abertura política para a recuperação das instituições democráticas abolidas no chamado Regime Militar, iniciado em 1964, que impunha, desde aquele ano, um regime de exceção e de censura às instituições nacionais.

A redemocratização significava, na época, o processo de restauração da democracia e do Estado de direito, e, principalmente, a eliminação do regime ditatorial. Nesse período, o momento foi marcado por reivindicações de envolvimento ativo nas discussões, tanto em âmbito nacional como internacional, fazendo com que a participação dos movimentos se tornasse visível nesse processo (SCHERER-WARREN, 2012). Nas décadas de 1980 e 1990, com a transição política para a democratização do Estado, ocorre uma afirmação e regulamentação de direitos. Segundo Scherer-Warren (2012), os movimentos sociais têm papel fundamental nesse processo.

No que diz respeito ao campo, além do período ditatorial repressivo, que contribuiu para a emergência dos movimentos, outros elementos das conjunturas política e social deste período histórico impulsionaram o surgimento desses atores coletivos. As exigências tecnológicas na agricultura, visando à produção voltada para o mercado, e não mais para a subsistência da família, fizeram com que os agricultores adotassem novas práticas produtivas, transformando seu modo de vida, produção e reprodução social (POLI, 2008). Os movimentos sociais do campo, na região oeste de Santa Catarina, emergem neste contexto de mudanças na vida dos agricultores, atrelados à pauperização das famílias, ao êxodo rural e à precariedade nas condições de trabalho decorrentes desse modelo.

A preocupação dos movimentos sociais camponeses culminou no pontapé inicial da trajetória de diferentes sujeitos articulados, dentre os quais destacamos, no oeste catarinense, o Movimento de Oposição Sindical; o Movimento das Mulheres Agricultoras 
(MMA), atualmente reconhecido como MMC; o MAB e o MST (POLI, 2008). Os movimentos sociais no campo sempre estiveram relacionados uns aos outros, na medida em que muitas das questões tratadas por eles são comuns, constituindo a perspectiva de redes (SCHERERWARREN, 2012).

Na década de 2000, consolida-se uma perspectiva de redes de movimentos sociais que, articulados entre si, evidenciam, na esfera pública, nova presença de engajamento com as questões nacionais e com maior autonomia em relação à esfera governamental. Os diferentes atores sociais, ao perceberem que, na esfera estatal, os jogos de poder nem sempre são favoráveis à cidadania, buscam, cada vez mais, a atuação em redes de movimentos sociais, revendo e transformando suas concepções de luta e enfrentando desafios conjuntamente (SCHERER-WARREN, 2012).

A referida autora aponta que essa nova forma de fazer política dos movimentos sociais em rede tende a contribuir para um processo de maior autonomia das forças populares em relação ao Estado. Para ela, a Via Campesina, que articula diferentes movimentos sociais do campo, dentre eles o MMC, caracteriza-se como uma rede transnacional.

Na mesma direção, Altieri (2010) aponta que a Via Campesina se dedica a debater e construir princípios e diretrizes em temáticas que são comuns aos diferentes movimentos articulados à rede, sendo a soberania alimentar um ponto em comum, defendido por todos. Sendo este tema uma ênfase do presente artigo, a seguir, são apresentadas algumas considerações no intuito de contribuir com a análise a partir do viés do MMC.

\subsection{A soberania alimentar como uma estratégia de luta}

Para auxiliar na compressão do conceito de soberania alimentar, Collet e Cima (2015) resgatam a contribuição do brasileiro Josué de Castro, que já em 1956 publicou a 1a edição da obra "Geografia da Fome", denunciando a ideologia dominante, que tratava a fome como um fenômeno natural. Para as autoras, o brasileiro foi corajoso ao questionar a visão hegemônica sobre o tema, afirmando "[...] que a fome era um problema social, resultante da forma de organização social da produção e distribuição dos alimentos [...]. Sua teoria 
provocou inúmeros debates e conflitos entre governos, instituições e estudiosos por longo tempo" (COLLET; CIMA, 2015, p. 48).

A partir da II Guerra Mundial, surge o conceito de segurança alimentar, quando mais da metade da Europa estava devastada e sem condições de produzir o seu próprio alimento. Esse conceito tem presente três critérios fundamentais: quantidade, qualidade e regularidade no acesso aos alimentos (BELIK, 2003).

Mas foi somente no final do século XX que os governos e a Organização das Nações Unidas para a Alimentação e Agricultura (FAO) assimilaram a urgência e necessidade de assumir o conceito de segurança alimentar, incorporando-a à perspectiva de direito. Assim, Collet e Cima (2015) apontam que, a partir deste marco, compreende-se que os sujeitos têm direito ao alimento, cabendo ao Estado a implementação de políticas que garantam o seu acesso.

Destaca-se que as pressões da sociedade civil organizada por meio de movimentos sociais, de Igrejas, de Organizações Não-Governamentais (ONGs), de grupos de estudiosos contribuíram para que os governos assumissem o conceito de segurança alimentar (COLLET; CIMA, 2015). O envolvimento dos diferentes movimentos sociais denota o paradigma do processo político, que Tarrow (2009) compreende enquanto expressão de poder dos sujeitos, buscando, no campo das relações entre Estado e sociedade, visibilizar suas questões e demandas.

Collet e Cima (2015) afirmam, entretanto, que o processo de mobilização e reflexão, propiciado pela organização da sociedade civil, demonstrou que o conceito de segurança alimentar é válido, mas, por si só, é insuficiente para resolver o problema da fome. Isto porque as preocupações das políticas públicas demonstravam limitação no sentido de garantia dos alimentos, sem se importar como e onde são produzidos, favorecendo o agronegócio e as políticas agrícolas neoliberais desenvolvidas em todo o mundo.

Na mesma perspectiva, Stédile e Carvalho (2011), ao descreverem a história do conceito de soberania alimentar, apontam que assumir a ideia de segurança alimentar foi um passo importante, na medida em que se constituiu como uma política pública que impulsionou os governos, mesmo que de forma obrigatória, a buscarem atender às demandas relacionadas à fome de sua população. Apesar do reconhecimento da 
importância dessas conquistas, o debate das organizações camponesas avançou para a construção do conceito de soberania alimentar.

Em 1996, durante o Encontro da Cúpula Mundial pela Alimentação (CMA), realizada em Roma pela FAO, a Via Campesina conquistou respeito e atenção de outros atores sociais, incluindo ONGs e movimentos sociais urbanos, quando divulgou publicamente o conceito de soberania alimentar. A rede de movimentos sociais que forma a Via Campesina levou seis anos para elaborar este conceito, por meio de negociações e diálogo entre as diversas organizações que a compõem em níveis local, regional e global (STÉDILE; CARVALHO, 2011).

Collet e Cima (2015) assinalam a contribuição significativa das mulheres camponesas que identificaram que o problema da forme não está relacionado unicamente à distribuição e ao acesso aos alimentos por parte da população empobrecida. Está, principalmente, relacionado a um problema de soberania nacional, "[..] onde os povos de cada território têm direito ao acesso e à produção dos alimentos próprios do seu bioma, garantindo a reprodução social, modos de vida, hábitos, costumes locais, entre outros" (COLLET; CIMA, 2015, p. 49).

A apresentação do conceito de soberania alimentar proposta pela Via Campesina pretendia ser um contraponto ao conceito de segurança alimentar, partindo do princípio de que o alimento não deve estar no patamar de mercadoria, mas de direitos humanos, assim como a produção e distribuição devem ser entendidas como uma questão de sobrevivência dos sujeitos. Nesta perspectiva, Stédile e Carvalho (2011) corroboram a noção de que, além do acesso aos alimentos, a população de cada país deve ter o direito de produzi-los, sendo que a garantia da soberania somente ocorrerá se os povos puderem ter o controle sobre a produção de seus alimentos, respeitando o meio em que vivem e se reproduzem socialmente.

Santos e Santos (2015) afirmam que a soberania alimentar, na abordagem da Via Campesina, favorece a soberania econômica, política e cultural dos povos, e sua defesa reconhece nos camponeses, indígenas e comunidades pesqueiras importantes atores sociais na definição de estratégias sustentáveis de produção, distribuição e consumo de alimentos baseados na pequena e média produção. 
Convergente com esta perspectiva, Altieri (2010, p. 30) entende que

\begin{abstract}
Os movimentos sociais rurais abraçam o conceito de Soberania Alimentar como uma alternativa ao método neoliberal que acredita num comércio internacional injusto para solucionar o problema da comida no mundo. A Soberania Alimentar se enfoca na autonomia local, nos mercados locais, nos ciclos locais de produçãoconsumo, na soberania energética e tecnológica e nas redes de agricultor a agricultor.
\end{abstract}

A Via Campesina, na perspectiva de rede de movimentos sociais, vem atuando conjuntamente nos níveis local, regional, nacional e global. Esta vem dedicando-se aos seguintes pontos principais: soberania alimentar, reforma agrária, gênero, recursos genéticos, biodiversidade, direitos humanos, desenvolvimento rural, direito dos trabalhadores, agricultura sustentável, migração e, mais recentemente, ao tema da energia (ALTIERI, 2010).

Entende-se, a partir do exposto, que é imprescindível pensar no acesso e no controle dos meios de produção para se garantir a soberania alimentar. E isso se constrói a partir da recuperação das sementes crioulas, com a produção de alimentos saudáveis por meio da agroecologia, com respeito à diversidade local, regional. E, principalmente, com o respeito aos diferentes atores sociais inseridos nesse contexto (COLLET; CIMA, 2015). O MMC, como integrante da Via Campesina, atua juntamente com outros movimentos sociais na defesa do projeto de soberania alimentar. Devido a este movimento específico ser objeto de análise proposto neste estudo, cabe voltar o olhar para a realidade do MMC e suas ações no que diz respeito ao tema.

\title{
3 Movimento de mulheres camponesas: trajetória e bandeiras de luta
}

O MMC é uma organização de mulheres residentes/trabalhadoras do campo, que emerge em diferentes regiões do Brasil, juntamente com a efervescência de outros movimentos sociais, durante a década de 1980 (POLI, 2008). Em Santa Catarina, foi inicialmente denominado como MMA e oficialmente reconhecido como MMC, em 2004, apresentando-se, desde então, como um movimento autônomo, de base camponesa e feminista, que visa fortalecer um processo de emancipação e de luta pelos direitos das mulheres camponesas. 
Boni (2013) sinaliza o protagonismo das mulheres do campo, que carregam essa bagagem de mais de três décadas de história de lutas e reivindicações, resultando em conquistas importantes no que diz respeito aos direitos das mulheres camponesas. Poli (2008) e Cinelli (2013) ressaltam que as questões de gênero sempre estiveram presentes no campo, porém ganharam força na medida em que as mulheres reconheceram as relações de opressão, tanto no que se refere ao reconhecimento de seus direitos trabalhistas e de agricultoras, quanto à sua condição de ser mulher.

Evidencia-se, conforme aponta Melucci (2001), a constituição da identidade coletiva em torno de um "nós", que não resulta de um processo individual, mas se refere à construção histórica do ser mulher, compartilhada por um grupo que vivencia esta condição. A percepção de compartilhar uma determinada condição permite a identificação voltada para causas em comum, possibilitando, também, a percepção da relação de dominação, anteriormente vivenciada como uma realidade inquestionável. Nesse sentido, o MMC está engajado na proposta do feminismo que, "[...] além de ser uma atitude política que analisa as relações de gênero, étnico-raciais e de classe, realiza o enfrentamento ao patriarcado e busca a construção de uma sociedade igualitária com a socialização do poder, das riquezas e do saber" (AMTR, 2008, p. 15).

Até a criação do MMC, em 2004, os estados brasileiros mantinham organizações de mulheres camponesas de forma isolada, como o MMA, em Santa Catarina; o Movimento de Mulheres Trabalhadoras Rurais (MMTR) no Rio Grande do Sul e Paraná; das extrativistas, no norte e nordeste do Brasil (BONI, 2013). Na década de 1990, houve uma articulação entre os diferentes movimentos e criou-se a Articulação Nacional de Mulheres Trabalhadoras Rurais (ANMTR), resultando na criação do MMC, que passou a incorporar a Via Campesina. Esta mudança de nomenclatura deve-se à ressignificação de termos utilizados anteriormente pelo movimento, como "agricultoras" e "trabalhadoras rurais", que passaram a ser substituídos pelo conceito de camponesas, abarcando de forma abrangente todas as mulheres que vivem no campo (BONI, 2013; CINELLI, 2013).

É interessante destacar que Paulilo (2007), em entrevista realizada com uma integrante do $\mathrm{MMC}$, resgata uma crítica antiga dirigida às mulheres do $\mathrm{MMC}$ por outras organizações sociais, relacionada ao fato de se reunirem entre si, sem a participação masculina. Essas organizações acreditavam que as mulheres deveriam se articular aos outros 
movimentos, pois a forma como estavam se organizando prejudicaria uma luta maior e "mais importante", baseada nas questões de classe, relegando às questões de gênero a noção de complementaridade.

Muitas vezes, o movimento foi questionado, inclusive por entidades internacionais, sobre por que ter um movimento só de mulheres. Conforme pode ser observado nas palavras da informante entrevistada por Paulilo (2007), fica claro o posicionamento do MMC em relação a isso:

\begin{abstract}
Nesses movimentos mistos, nos poderes de decisão estão geralmente os homens. São poucas mulheres que estão nos espaços onde se decidem as coisas. As mulheres são muito mais tarefeiras, mandadas pelos homens, do que ocupando espaços de decisão. E nós queremos um espaço onde nós decidimos, por isso nós achamos importante um movimento só de mulheres. Num movimento misto, onde está o homem e a mulher, muitas vezes, a mulher se cala e não fala o que talvez ela gostaria de falar. E num espaço só de mulheres, nós achamos que é mais fácil as mulheres se abrirem (entrevista cedida a PAULILO, 2007, p. 411).
\end{abstract}

O fato de se constituir como um movimento autônomo não significa que não ocorra integração e articulação com os demais movimentos. Boni (2013) afirma que, ao mesmo tempo em que as mulheres garantiam a autonomia de seu movimento por meio de reuniões e assembleias, também se articulavam com Sindicatos de Trabalhadores Rurais, Movimento dos Pequenos Agricultores (MPA), MST, além de movimentos urbanos. Nessas reivindicações coletivas, a ênfase recai sobre as políticas públicas para as(os) camponesas(es) e agricultoras(es) familiares.

Uma das principais bandeiras de luta do MMC refere-se à defesa da vida, considerando a busca pela justiça, liberdade e solidariedade. Entre as prioridades do movimento, destaca-se a construção de um projeto de agricultura agroecológica, em contraposição ao modelo de produção em larga escala, nos moldes do agronegócio extensivo, denominado pela literatura como agricultura convencional.

O projeto de agroecologia defendido pelas mulheres camponesas consiste em um conjunto de conhecimentos "[...] capaz de dar suporte aos processos de transição para estilos de agricultura sustentáveis" (SILIPRANDI, 2013, p. 330). A autora aponta que os principais teóricos que discutem o tema definem agroecologia como a integração de diversas disciplinas científicas, por meio das quais se analisa e se atua sobre os 
agroecossistemas, permitindo a implantação de estilos de agricultura com maior nível de sustentabilidade.

Ao mesmo tempo, o projeto de agroecologia visa atuar no enfrentamento e negação de uma sociedade ainda marcada pelo patriarcalismo e machismo, tanto no campo quanto na cidade, vislumbrando mudanças significativas nas relações entre homens e mulheres. Valoriza os sujeitos, e aqui mais especificamente as mulheres, como protagonistas na construção desse modelo, possibilitando um diálogo de saberes entre os conhecimentos científico e popular (SILIPRANDI, 2013). O movimento desenvolve campanhas e incentiva a produção de alimentos saudáveis e diversificados por meio da agroecologia como possibilidade de se garantir a ideia de soberania alimentar.

3.1 A soberania alimentar como princípio orientador de ações do MMC

A construção de uma sociedade com novas relações entre as pessoas e das pessoas com o ambiente que ocupam, ideia basilar no alcance da soberania alimentar, vem representando parte das ações do MMC em sua defesa. As mulheres organizadas no MMC, quando propõem a soberania alimentar como princípio orientador de suas ações e práticas produtivas, assumem algumas questões específicas, como a preservação do solo, a recuperação de sementes crioulas e o plantio e manejo agroecológico. O entendimento é o de que "[...] não é apenas um conceito, mas uma estratégica política de enfrentamento ao sistema neoliberal globalizado" (COLLET; CIMA, 2015, p. 50), que confere o status de mercado às diferentes dimensões da vida.

Refletindo, a partir de suas vivências, as mulheres camponesas aprofundam os debates, envolvendo a "[...] inter-relação entre solo - produção - alimentação - saúde" (AMTR - Sul, 2008, p. 53). O MMC tem-se responsabilizado por desafiar e propor para a sociedade a necessidade de assumir a luta pela alimentação saudável, lançando campanhas relacionadas ao tema, que fomentam e reafirmam o princípio da soberania alimentar.

As mulheres inseridas no MMC se organizam a partir de quintais produtivos, praticando os princípios, os valores e a ética da soberania alimentar. Estes quintais produtivos agroecológicos são, de acordo com Collet e Cima (2015), espaços de terra que agrupam diferentes elementos, como as hortas, hortos medicinais, pomares, reprodução e 
criação de animais de pequeno porte, captação da água da chuva, dentre outros. Geralmente são espaços gerenciados pelas mulheres.

Na produção dos quintais produtivos, além da organização e separação do que é necessário para o autossustento, as mulheres fazem também a partilha dos alimentos colhidos com vizinhos e familiares e encaminham o excedente para a comercialização ou troca de alimentos processados (COLLET; CIMA, 2015). Assim, elas possibilitam imprimir ações concretas e reais aos princípios da soberania alimentar, em níveis local e regional, em que demonstram ser possível controlar suas sementes, terra e água, garantindo que a produção local seja variada e nutritiva, além de acessível e compartilhada entre as pessoas da mesma comunidade.

Collet e Cima (2015) revelam que os quintais produtivos reúnem diversidade, evidenciando, inclusive, uma dimensão pedagógica que pode ser utilizada para a educação dos filhos (as), configurando-se como um instrumento de resistência e luta que começa em casa, como uma forma de enfrentamento ao modelo hegemônico de produção. Pode ser considerado como um espaço de produção contra-hegemônico, na medida em que visa a uma produção livre de venenos, de transgênicos, da monocultura, da uniformização da alimentação, do domínio dos sistemas de integração com as agroindústrias, caracterizandose como uma importante contribuição das mulheres na garantia da soberania alimentar dos povos (COLLET; CIMA, 2015).

As práticas cotidianas das mulheres camponesas de cultivo e produção não encerram as ações relacionadas à soberania alimentar do MMC. Para além das propriedades individuais, em que colocam em prática os princípios da soberania alimentar, a partir dos preceitos da agricultura camponesa e agroecológica, o movimento debate fortemente a questão, evidenciando novamente a expressão de poder expressa no campo da política, assinalado por Tarrow (2009). Isto tem sido realizado a partir de formações, capacitações, eventos promovidos pelo próprio $\mathrm{MMC}$ ou articulados com outros movimentos e organizações sociais. Esses tensionamentos provocados pelos diferentes atores sociais são responsáveis pelas modificações nas relações entre Estado e sociedade, sendo que o primeiro não pode se eximir de ouvir as respostas às demandas exigidas pela população.

Verifica-se também a existência de materiais produzidos pelo $M M C$, difundidos entre suas integrantes, que visam fortalecer suas bandeiras de luta. No que se refere ao tema da 
soberania alimentar, cartilhas, folders, revistas e jornais trazem publicações chamando as mulheres para a produção de alimentos saudáveis, para a agroecologia, para os exemplos e experiências de produção que estão trazendo bons resultados para as famílias. Realizam cruzamento de temas, como feminismo e agroecologia, autonomia das mulheres nas propriedades e na vida, ratificando a identidade coletiva de ser mulher em uma sociedade indiscutivelmente marcada pelo machismo e patriarcalismo, rememorando os postulados de Melucci (2001) sobre a construção de uma identidade em comum.

É importante destacar, a partir da leitura dos materiais difundidos pelo movimento, que o MMC atua em nível nacional e, por este motivo, os mesmos princípios e valores orientadores das práticas das mulheres são contemplados em diferentes regiões do país. Diferenciam-se apenas em relação ao que se produz devido à realidade local, mas entendendo que os enfrentamentos e embates necessários são em nível macro: nacional, no que se refere às bandeiras de luta específicas do $M M C$, e internacionais, quando observadas as questões comuns com outros movimentos e com a rede de movimentos sociais na qual está inserida (Via Campesina).

Retomando Scherer-Warren (2012) e Gohn (2006), a perspectiva de rede de movimentos sociais possibilita o enfrentamento conjunto das situações comuns aos diferentes grupos. A articulação dos movimentos sociais em rede fortalece e gera maior visibilidade aos temas, como é o caso da soberania alimentar, conceito construído e defendido por diferentes atores sociais em prol da produção de respostas à questão da fome no mundo, que já começa com as iniciativas locais que observamos nas dinâmicas regionais do oeste catarinense.

\section{Considerações finais}

Os movimentos sociais têm um papel determinante nos processos sociais, na medida em que transformaram e continuam transformando a realidade local. Isso se deve à sua forte ação na política interna e nos espaços representativos, para os quais emergem as pautas e reivindicações dos grupos sociais aos quais representam. Considerando a especificidade do movimento estudado, constata-se que o MMC, ao incorporar a concepção de agroecologia na defesa da soberania alimentar, oportuniza às mulheres e às suas famílias 
uma reelaboração no jeito de fazer agricultura, transformando seu modo de vida e possibilitando olhares para as dinâmicas e processos regionais.

A proposta de soberania alimentar, presente nas reflexões e práticas das mulheres camponesas do MMC, evidencia a importância da construção de modelos de agricultura alternativa, necessários para a superação de modelos convencionais. Tal proposta se apresenta como ecológica, biodiversa, local, sustentável e socialmente justa, na medida em que se apoia em uma racionalidade ecológica da agricultura tradicional em pequena escala, que representa exemplos de sistemas que alimentaram a maior parte da população do mundo durante séculos, e seguem alimentando milhões de pessoas em muitas partes do planeta.

Com a bandeira de defesa da vida, o MMC prioriza questões relativas às mulheres e às famílias que vivem e se reproduzem socialmente no campo, realizando a articulação de temas como a agroecologia e o feminismo. Vislumbram, na defesa desse projeto, a possibilidade de mudanças estruturais nas relações entre homens e mulheres, e destes com o meio em que vivem. O movimento busca a valorização dos sujeitos, principalmente das mulheres, como protagonistas na construção do modelo de soberania alimentar, articulando saberes científicos e populares em torno do tema (SILIPRANDI, 2013).

A elaboração coletiva do conceito de soberania alimentar desvela a perspectiva do trabalho em redes de movimentos sociais (SCHERER-WARREN, 2012), como pode ser verificado na articulação dos diferentes movimentos do campo por meio da Via Campesina. Nesse processo, é importante ressaltar a contribuição das mulheres campesinas, identificando que o problema da forme não se deve unicamente à distribuição e acesso ao alimento, mas se configura como uma problemática de soberania nacional. Ou seja, o modelo convencional de agricultura retira dos povos o direito ao acesso e produção de alimentos que são próprios do seu bioma.

Do ponto de vista do $\mathrm{MMC}$ e dos demais movimentos sociais vinculados à Via Campesina, somente quando os povos controlam os meios de produção do próprio alimento, respeitando o meio no qual vivem, reproduzem-se socialmente, preservando seus modos de vida, hábitos e costumes, podemos falar em soberania (STÉDILE; CARVALHO, 2011). Outro consenso entre os movimentos sociais do campo quanto ao tema da soberania alimentar é considerar o alimento como direito humano fundamental, sendo este um motivo 
pelo qual se atua em rede, defendendo, construindo e colocando em prática o projeto compartilhado por todos.

\section{Referências}

ALTIERI, Miguel A. Agroecologia, agricultura camponesa e soberania alimentar. Revista Nera. v. 13, n. 16, jan./jun./2010. Disponível em: <http://revista.fct.unesp.br/index.php/nera/ article/view/1362/1347>. Acesso em: 20 nov. 2015.

AMTR-SUL - Articulação de Mulheres Trabalhadoras da Região Sul do Brasil. (Org.) DARON, Vanderleia L. P.; COLLET, Zenaide. Cartilha: Mulheres camponesas em defesa da saúde e da vida. Passo Fundo: Gráfica Passografic, 2008.

ARAUJO, Nayra V.; LIMA, Antônia J. Melucci e Tarrow: revisão teórica sobre movimentos sociais. Revista em Pauta, Rio de Janeiro. v. 7, n. 25, p. 115-130, jul. 2010.

BELIK, W. Perspectivas para Segurança Alimentar e nutricional no Brasil. Saúde e Sociedade, São Paulo, v .12, n. 1, p. 12-20, jan./jun. 2003.

BONI, Valdete. MMC um movimento camponês e feminista. Grifos. Chapecó. v. 22,: Argos, p.34-35. 2013. Disponível em: <http://bell.unochapeco.edu.br/revistas/index.php/grifos/ article/view/1259>. Acesso em: 28 nov. 2015.

COLLET, Zenaide. CIMA, Justina I. Produção de auto sustento, quintais produtivos na agricultura familiar e camponesa. In: BONI, Valdete (Org.). Organização produtiva de mulheres e promoção de autonomia por meio do estímulo à prática agroecológica. Tubarão: Gráfica Copiart, 2015.

CINELLI, Catiane. Movimento de Mulheres Camponesas: 30 anos. In: Grifos. Chapecó: Argos; 2013.

GOHN, Maria da Glória. Teorias dos movimentos sociais: paradigmas clássicos e contemporâneos. São Paulo: Loyola, 2006.

. Movimentos sociais na contemporaneidade. Revista Brasileira de Educação. São

Paulo, v. 16, n. 47, 2011. Disponível em:

http://www.scielo.br/pdf/rbedu/v16n47/v16n47a05.pdf. Acesso em: 1 dez. 2015.

GOSS, Karine Pereira; PRUDENCIO, Kelly. O conceito de movimentos sociais revisitado. Em Tese, Florianópolis, v. 1, n. 2, p. 75-91, jan. 2004. ISSN 1806-5023. Disponível em:

<https://periodicos.ufsc.br/index.php/emtese/article/view/13624/12489>. Acesso em: 15 ago. 2016. 
MELUCCl, Alberto. A invenção do presente: movimentos sociais nas sociedades complexas. Petrópolis: Vozes, 2001.

PAULILO, Maria Ignez. A luta das mulheres agricultoras: entrevista com Adélia Schmitz. Revista Estudos Feministas, Florianópolis, 2007.

POLI, Odilon. Leituras em movimentos sociais. Chapecó: Argos, 2008.

SANTOS, L. R. S.; SANTOS, J. L. A soberania alimentar: construção política desde a organização das mulheres camponesas. In: Boletim DATALUTA. Núcleo de Estudos, Pesquisa e Projetos de Reforma Agrária. São Paulo: NERA, 2015. Disponível em: <http://www2.fct.unesp.br/nera/artigodomes/5artigodomes_2015.pdf>. Acesso em: 28 nov. 2015.

SCHERER-WARREN, Ilse. Movimentos sociais e Estado no Brasil: da ditadura a democratização. In: SCHERER-WARREN, Ilse. Redes emancipatórias: nas lutas contra a exclusão e por direitos humanos. Curitiba: Appris, 2012. p. 53-63.

SILIPRANDI, Emma. Mulheres agricultoras e a construção dos movimentos agroecológicos no Brasil. In: NEVES, Delma P.; MEDEIROS, Leonilde S. (Orgs.). Mulheres camponesas: trabalho produtivo e engajamentos políticos. Niterói: Alternativa, 2013.

STÉDILE, João Pedro; CARVALHO, Horácio Martins de. Soberania Alimentar: uma necessidade dos povos. Brasília, Biblioteca digital da questão agrária do Brasil. 2011. Disponível em: $<$ http://www.reformaagrariaemdados.org.br/sites/default/files/Soberania\%20Alimentar\%20 -\%20Uma\%20necessidade\%20dos\%20povos\%20-\%20Jo\%C3\%A3o\%20Pedro\%20Stedile\% 20e\%20Horacio\%20Martins\%20de\%20Carvalho\%20-\%202010.pdf>. Publicado em 25 de março de 2011. Acesso em: 28 nov. 2015. 